Research article

\title{
Human antimicrobial protein hCAP18/LL-37 promotes a metastatic phenotype in breast cancer
}

\author{
Günther Weber ${ }^{1}$, Clara Ibel Chamorro², Fredrik Granath², Annelie Liljegren³, Sami Zreika', \\ Zuzana Saidak4, Bengt Sandstedt³ ${ }^{3}$, Samuel Rotstein ${ }^{3}$, Romuald Mentaverri4 ${ }^{4}$ Fabio Sánchez², \\ Andor Pivarcsi² and Mona Ståhle²
}

${ }^{1}$ GICC, UMR CNRS 6239, Université François Rabelais, Avenue Monge, Tours, 37 100, France

2Unit of Dermatology and Venereology, Department of Medicine, Karolinska Institutet, CMM:02, Stockholm, 171 76, Sweden

${ }^{3}$ Department of Oncology and Pathology, Karolinska Institutet, Stockholm, 171 76, Sweden

${ }^{4}$ INSERM, ERI-12, Faculty of Pharmacy, 1 Rue des Louvels, Amiens, 80 037, France

Corresponding author: Mona Ståhle, mona.stahle@ki.se

Received: 12 Aug 2008 Revisions requested: 4 Sep 2008 Revisions received: 16 Jan 2009 Accepted: 30 Jan 2009 Published: 30 Jan 2009

Breast Cancer Research 2009, 11:R6 (doi:10.1186/bcr2221)

This article is online at: http://breast-cancer-research.com/content/11/1/R6

(c) 2009 Weber et al.; licensee BioMed Central Ltd.

This is an open access article distributed under the terms of the Creative Commons Attribution License (http://creativecommons.org/licenses/by/2.0), which permits unrestricted use, distribution, and reproduction in any medium, provided the original work is properly cited.

\begin{abstract}
Introduction Human cathelicidin antimicrobial protein, hCAP18, and its C-terminal peptide LL-37 is a multifunctional protein. In addition to being important in antimicrobial defense, it induces chemotaxis, stimulates angiogenesis and promotes tissue repair. We previously showed that human breast cancer cells express high amounts of hCAP18, and hypothesised that hCAP18/LL-37 may be involved in tumour progression.

Methods $h$ CAP18 mRNA was quantified in 109 primary breast cancers and compared with clinical findings and ERBB2 mRNA expression. Effects of exogenous LL-37 and transgenic overexpression of hCAP18 on ErbB2 signalling were investigated by immunoblotting using extracts from breast cancer cell lines ZR75-1 and derivatives of MCF7. We further analysed the impact of hCAP18/LL-37 on the morphology of breast cancer cells grown in soft agar, on cell migration and on tumour development in severe combined immunodeficiency (SCID) mice.
\end{abstract}

Results The expression of $h C A P 18$ correlated closely with that of $E R B B 2$ and with the presence of lymph node metastases in oestrogen receptor-positive tumours. hCAP18/LL-37 amplified Heregulin-induced mitogen-activated protein kinase (MAPK) signalling through ErbB2, identifying a functional association between hCAP18/LL-37 and ErbB2 in breast cancer. Treatment with LL-37 peptide significantly stimulated the migration of breast cancer cells and their colonies acquired a dispersed morphology indicative of increased metastatic potential. A truncated version of LL-37 competitively inhibited LL-37 induced MAPK phosphorylation and significantly reduced the number of altered cancer cell colonies induced by LL-37 as well as suppressed their migration. Transgenic overexpression of hCAP18 in a low malignant breast cancer cell line promoted the development of metastases in SCID mice, and analysis of hCAP18 transgenic tumours showed enhanced activation of MAPK signalling.

Conclusions Our results provide evidence that hCAP18/LL-37 contributes to breast cancer metastasis.

\section{Introduction}

The human cathelicidin antimicrobial protein hCAP18 is the single human member of the mammalian cathelicidin family of proteins [1]. The holoprotein consists of a conserved prodomain, cathelin and the non-conserved C-terminal peptide LL37 , which is enzymatically cleaved after secretion [2-4].
Consistent with a role in the first line of defense, hCAP18/LL37 is widely expressed in leucocytes and in epithelial cells $[5,6]$. Although initially identified purely as an antimicrobial protein, hCAP18/LL-37 is multifunctional with diverse and significant effects on eukaryotic cells. Thus, LL-37 transactivates the epidermal growth factor receptor (EGFR) inducing

ANOVA: analysis of variance; BSA: bovine serum albumin; DMEM: Dulbecco's modified eagle's media; eGFP: enhanced green fluorescent protein; EGFR: epidermal growth factor receptor; ER: oestrogen receptor; FACS: fluorescence-activated cell sorting; FCS: fetal calf serum; FPRL-1: formyl peptide receptor like-1; hCAP: human cathelicidin antimicrobial protein; HLA: human leucocyte antigen; HPLC: high-performance liquid chromatography; HRG: heregulin $\beta 3$; MAPK: mitogen-activated protein kinase; PBS: phosphate buffered saline; RT-PCR: reverse-transcription polymerase chain reaction; SCID: severe combined immunodeficiency. 
cytokine release and cell migration $[7,8]$ and stimulates chemotaxis and angiogenesis through the G-protein coupled receptor, the formyl peptide receptor like-1 (FPRL-1) [9-11]. In line with these findings, current research indicates that hCAP18/ LL-37 is actively involved in tissue repair and wound healing $[12,13]$ processes that share fundamental biological features with tumour growth and progression [14].

Antimicrobial proteins, including hCAP18/LL-37, have primarily been proposed as potential anti-tumour agents based on their cytotoxic effects at high concentration $[15,16]$. However, in a previous study comprising 28 breast cancer samples, we reported that hCAP18/LL-37 was upregulated in breast cancer cells with a correlation between hCAP18 protein levels and tumour grade, whereas in normal mammary tissue it was produced at a low level [17]. We also found that treatment with LL-37 peptide stimulated the proliferation of epithelial cells suggesting that LL-37 may act as a growth factor. Recent findings in lung and ovarian cancer show that overexpression of hCAP18/LL-37 also occurs in other cancer forms and may promote tumour growth $[18,19]$.

Based on our previous study, we were prompted to further explore the role of hCAP18/LL-37 in breast cancer. Here we report the coexpression of $h C A P 18$ and ERBB2 in breast tumours and their functional cooperation in vitro and in a mouse model.

\section{Materials and methods Patients and samples}

Breast cancer samples were collected consecutively from patients treated at Danderyd's Hospital, Stockholm, Sweden between 1994 and $1998(n=145)$. Thirty-six samples were excluded due to lack of information about oestrogen receptor (ER) status, lymph node status and/or RNA. The remaining 109 tumours were scored following established guidelines, and ER status was assessed on routinely processed paraffin sections. Healthy breast tissue was obtained from patients undergoing reconstructive surgery $(n=4)$. The study was approved by the regional committees of ethics and informed consent was obtained from patients and controls.

\section{Expression analysis of tumour RNA}

RNA from human breast cancers was extracted with Trizol (Invitrogen, Paisley, UK) and from mouse tumours with a column-based extraction kit (Bio-Rad Laboratories, Hercules, CA, USA). Random primed reverse transcription and real-time PCR (RT-PCR) analysis for $h$ CAP18 were performed as previously described, using $18 \mathrm{~S}$ RNA for normalisation [17]. ERBB2 transcription was quantified using an Assay-onDemand mixture (Applied Biosystems, Foster City, CA, USA).

\section{Statistical analyses}

Levels of $h$ CAP18 were compared with respect to lymph node and ER status by means of analysis of variance (ANOVA).
Pearson correlation coefficients were used to assess the association between $h C A P 18$ and ERBB2. All analyses were performed on logarithmically transformed data using the Statistical Analysis System package, version 9.1 (SAS Institute Inc, Cary, NC, USA). For quantitative evaluation of cell colonies grown in agar, experiments using eight plates for each condition were arranged in a factorial design and the resulting data analysed by ANOVA with the significance level set to $\alpha=$ 0.05 . For statistical evaluation of cell migration and mouse tumours and the occurrence of metastases, the non-parametric Mann-Whitney test was used.

\section{Cell lines}

ZR75-1 and MCF7 were obtained from ATCC (via LGC Promochem, Boras, Sweden). The cell line MJ1105 [20], derived from MCF7 cells, was kindly provided by Mikala Egeblad, UCLA, San Francisco, USA. Cells were stably transfected with a vector for bicystronic expression of enhanced green fluorescent protein (eGFP) and hCAP18 (cell line named MJ1105-hCAP) or with the empty eGFP-control (cell line named MJ1105-eGFP), selected by growing in OptiMEM supplemented with $10 \%$ FCS and G418 $(400 \mu \mathrm{g} / \mathrm{ml})$, enriched by fluorescence-activated cell sorting (FACS) selection for eGFP expression and maintained as described [17].

\section{Synthetic peptides}

LL-37, LL-25 and scrambled peptide were synthesised and purified by HPLC to a purity of $98 \%$ (Polypeptide Laboratories Hilleröd, Denmark, and GeneCust, Dudelange, Luxembourg). The biological activity of LL-37 was confirmed in an antibacterial assay (not shown).

\section{Mitogen-activated protein kinase activation assay}

All experiments were performed on at least two independent occasions. ZR75-1 cells or MJ1105 derivatives were plated in 12 -well plates at 100,000 cells per well, and starved for 48 hours in DMEM without FCS. Cells were stimulated with LL37 and/or Heregulin $\beta 3$ (HRG) recombinant protein (Upstate, Lake Placid, NY, USA). HRG was used at $2 \mathrm{ng} / \mathrm{ml}$ to optimise detection of synergism between HRG and LL-37. The inhibitors bisindolylmaleimide I, PD153035, GM6001, H89, PP2 (all Calbiochem, San Diego, CA, USA), N-acetylcystein, Tiron and pertussis toxin (all Sigma, St Louis, MO, USA), and WRW4 (Phoenix Pharmaceuticals, Belmont, CA, USA) were applied at the indicated concentrations 30 minutes before stimulation with LL-37 and/or HRG. Cells were washed 20 minutes after stimulation with ice-cold PBS containing $1 \mathrm{mM}$ sodium fluoride, $100 \mu \mathrm{M}$ sodium orthovanadate and $2 \mathrm{mM}$ phenylmethylsulphonylfluoride, and immediately lysed with sodium dodecylsulfate lysis buffer containing the respective inhibitor plus $50 \mathrm{mM}$ dithiothreitol.

\section{Protein detection}

Western blot analysis was essentially performed as described [13], using antibodies against phosphorylated and total pro- 
tein mitogen-activated protein kinase (MAPK) (Cell Signaling Technology, Beverly, LA, USA), phosphorylated and total protein ERBB2 (Upstate, Lake Placid. NY, USA), and hCAP18 [13], all at 1/2000 dilution. Enhanced chemiluminescence signals (Amersham Biosciences, Piscataway, NJ, USA) were captured by a charge-coupled device camera (Fujifilm, Tokyo, Japan) using Image Gauge (Fujifilm, Tokyo, Japan) for evaluation. Linearity of the signal within the range of our experiments was confirmed using a serial dilution. For normalisation, the Ponceau staining of the blot was scanned and the digitised picture evaluated with the same software. The linear portion of the signal was determined to occur between 5 and $100 \mu \mathrm{g}$ of total protein extract, therefore about $20 \mu \mathrm{g}$ was routinely applied.

Immunohistochemistry on cryostat sections from snap-frozen tumours was performed as described previously [13] with affinity purified rabbit anti-LL-37 antibodies at 1/6000 dilution. The presence of breast cancer cells in all tumours and metastases was verified by immunohistochemistry with anti-human leucocyte antigen (HLA) A/C antibodies (Serotec, Raleigh, NC, USA) at 1/40,000 dilution.

\section{Colony formation assay}

One thousand cells (MJ 1105 or ZR75-1) were suspended in $2 \mathrm{ml}$ of $0.35 \%$ melted agar in OptiMEM medium (Invitrogen, Carlsbad, CA. USA) with 5\% FCS plus LL-37/HRG, and plated in $50 \mathrm{~mm}$ gridded dishes containing a solidified layer of $0.7 \%$ agar in the same medium. After 12 days, the top layer of the culture was stained with $0.2 \% \mathrm{p}$-iodonitrotetrazolium violet (Sigma, St Louis, MO, USA). Colonies within a grid of $10 \times 10$ that were larger than $100 \mu \mathrm{M}$ in diameter (about 200 colonies/ plate) were counted and their morphology categorised. All evaluations were performed in a blinded manner. The experiments were independently performed three times.

\section{Cell migration assays}

The Boyden chamber migration assays were carried out in the presence or absence of LL-37 and/or LL-25. Briefly, cells were serum starved for four hours in $0.2 \%$ BSA containing $\alpha$-MEM medium. Cells were then trypsinised, harvested and resuspended in serum-free $\alpha$-MEM medium. Chemotactic activity was determined in a Boyden chamber system (Neuroprobe Inc, Gaithersburg, MD., USA) with a $8 \mu \mathrm{m}$ pore size polycarbonate membrane (Neuroprobe Inc, Gaithersburg, MD., USA) separating the two chambers. Serum-free $\alpha$-MEM alone or with LL-37 and/or LL-25 was added to the lower chamber with final concentrations of $2 \mu \mathrm{M}$ and $1 \mu \mathrm{M}$, respectively. Cells were loaded to the upper chamber at a concentration of $5 \times$ $10^{4}$ cells in $500 \mu \mathrm{l}$ of serum-free $\alpha$-MEM. Chambers were incubated at $37^{\circ} \mathrm{C}$ for five hours in a $95 \%$ air, $5 \%$ carbon dioxide atmosphere. The upper medium was then removed, the chamber was disassembled and membranes were fixed in $96 \%$ methanol for two minutes. The membranes were rinsed in distilled water and subsequently stained in Giemsa for two minutes, followed by two washing steps. Then, the cells on the upper side of the filters were cleaned off. Cells in the filter were counted under a microscope at a magnification of 20. To allow for comparison between multiple assays, the data were normalised and expressed as migration rate of the cells compared with the control chamber.

\section{Tumorigenicity studies in SCID mice}

The study was approved by the Animal Assurance Agency R5002-01 (ethical permits N421/04 and N235/05). MJ1105hCAP18 and MJ1105-eGFP cells were trypsinised and suspended in PBS $/ 1 \mathrm{mM}$ magnesium chloride at 50 million $/ \mathrm{ml}$. Ten million cells $(200 \mu \mathrm{l})$ were injected subcutaneously into the mouse. These cells require oestrogen for tumour formation, so slow-release $17-\beta$ oestradiol pellets $(1.7 \mathrm{mg}$ total dose; Innovative Research of America, Sarasota, FL, USA) were implanted the day before tumour cell injection. The test group injected with the hCAP18 transgenic cell line and the group injected with the control cell line each consisted of five mice. Mice were observed daily and palpated for tumour formation twice a week. Mice were sacrificed when the tumour reached about $1 \mathrm{~cm}^{3}$ in size. Tumours were excised and snap frozen, and used for immunohistochemistry, protein and RNA extraction as described. For detection of metastasising cells, spleen and liver were disaggregated to single cell suspensions, and after lysis of erythrocytes with $0.17 \%$ ammonium chloride and removal of debris by centrifugation, analysed for the presence of eGFP expressing cells by FACS analysis.

\section{Results \\ hCAP18 expression correlates with the expression of ERBB2 and is associated with lymph node metastasis in estrogen receptor positive human breast cancer}

Previously we have shown that $h C A P 18$ mRNA and protein are overexpressed in human breast cancer samples [17]. To explore its possible association with tumour development, we investigated $h$ CAP18 mRNA levels in an extended panel of human breast cancer samples $(n=109)$. Results of quantitative RT-PCR demonstrated that the average level of $h$ CAP18 mRNA expression was at least one order of magnitude higher in breast cancer tissues in comparison with normal breast tissue (Figure 1a,b). Of note, only eight out of the 109 tumours expressed $h C A P 18$ within the low range of control samples and none of these tumours had lymph node metastases at the time of surgery [see additional data file 1]. Stratifying the patient material based on ER expression, and the presence of lymph node metastasis we found that $h C A P 18$ expression was significantly higher $(\mathrm{p}<0.001)$ in ER-positive tumours ( $\mathrm{n}$ $=38$ ) with lymph node metastases than in tumours without lymph node metastasis $(n=42)$ associating the expression of hCAP18 with metastasis formation in breast cancer (Figure 1a). Although the expression of $h C A P 18$ was significantly greater in ER-negative tumours compared with control tissues, there was no clear association with lymph node metastasis at the time of primary surgery (Figure 1b). However, our results 
(a)

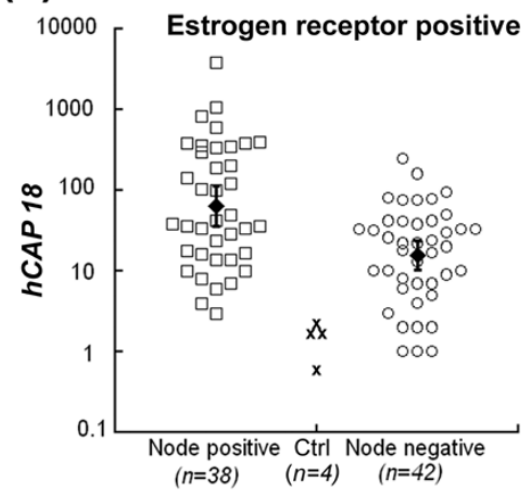

(c)

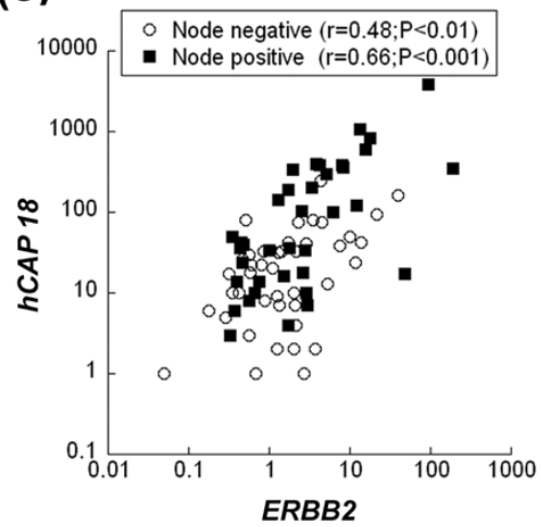

(b)

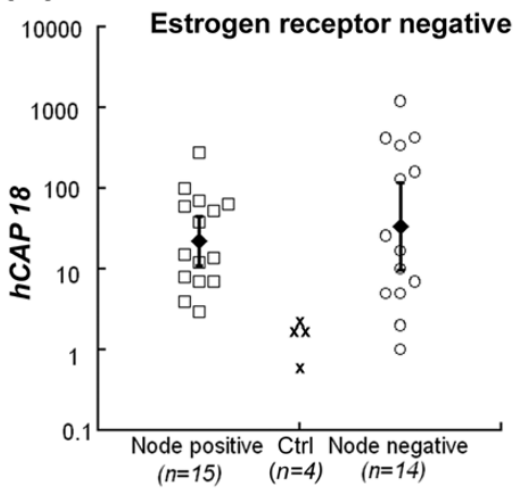

(d)

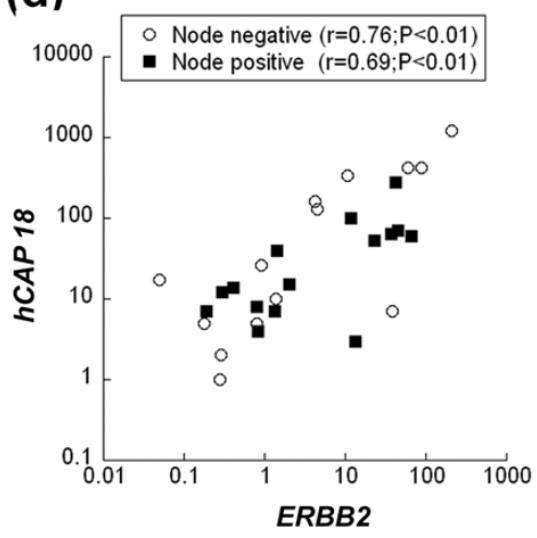

$h C A P 18$ transcript levels in relation to ERBB2 levels, lymph node status and oestrogen receptor (ER) status. All transcription levels determined by real-time reverse transcriptase PCR are displayed relative to the mean of four control samples. (a) Significantly higher levels of $h C A P 18$ transcript for lymph node positive compared with lymph node-negative ER-positive patients $(\mathrm{p}<0.001)$. (b) No significant difference in $h C A P 18$ levels with respect to lymph node status was observed for ER-negative patients $(a, b)$ filled markers and error bars represent geometric means and $95 \%$ confidence intervals. The association between $h C A P 18$ levels and lymph node status was significantly different for (a) ER-positive and (b) ER-negative patients $(\mathrm{p}=0.01)$. (c, d) Significant correlation between levels of $h C A P 18$ and ERBB2 was observed in all groups, whether (c) ER positive or (d) ER negative, and irrespective of lymph node status (squares versus circles).

indicate that high $h C A P 18$ expression is associated with lymph node metastasis at least in ER-positive human breast cancer.

Amplification and overexpression of the tyrosine kinase receptor gene $E R B B 2$ is a hallmark of metastatic development in breast cancer [21]. Because LL-37 has been linked to EGFR signalling $[7,8]$, we investigated if increased $h C A P 18$ expression was associated with changes in ERBB2 levels. Our data demonstrate a highly significant correlation between the expression of both genes in ER-positive as well as in ER-negative tumours (Figure 1c,d). Neither ERBB2 nor $h C A P 18$ transcription levels in breast cancer patients correlated with relapse or mortality after 5 to 10 years of follow-up (data not shown).
hCAP18 and ErbB2 are functionally connected in breast cancer cells

To investigate whether hCAP18 regulates the expression of $E R B B 2$, we established a transgenic cell line derivative from a low malignant ER-positive breast cancer line, MJ1105 [22], which has no amplification of ERBB2 and expresses hCAP18 at a low levels similar to those of normal mammary tissue. The low expression of ERBB2 remained unchanged [see additional data file 2], so we further investigated whether LL-37 had a functional influence on ERBB2. And because LL-37 is reported to induce phosphorylation of MAPK via the EGFR [7], we assessed its effect on signaling through ErbB2 using recombinant $\mathrm{HRG}$ as positive control. The experiments were carried out in MJ1105 and in the ER-positive breast cancer line ZR75-1 [22]. Both LL-37 and HRG induced phosphorylation of ERBB2 and MAPK in both cell lines (shown in Figure 2 for ZR75-1). When LL-37 and HRG were added together, a synergistic increase in MAPK phosphorylation was observed. 
(a)
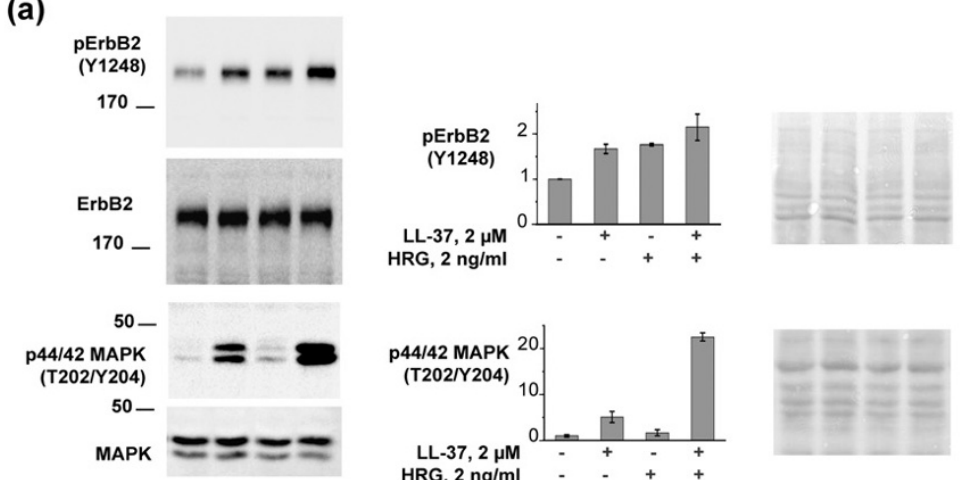

$\begin{array}{rllll}\mathrm{LL}-37,2 \mu \mathrm{M} & - & + & - & + \\ \mathrm{HRG}, 2 \mathrm{ng} / \mathrm{ml} & - & - & + & +\end{array}$
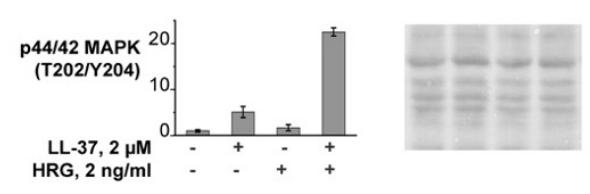

Ponceau

\section{(b)}
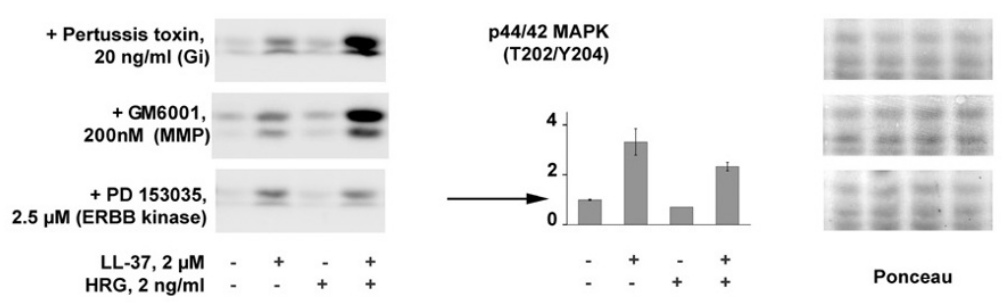

(c)
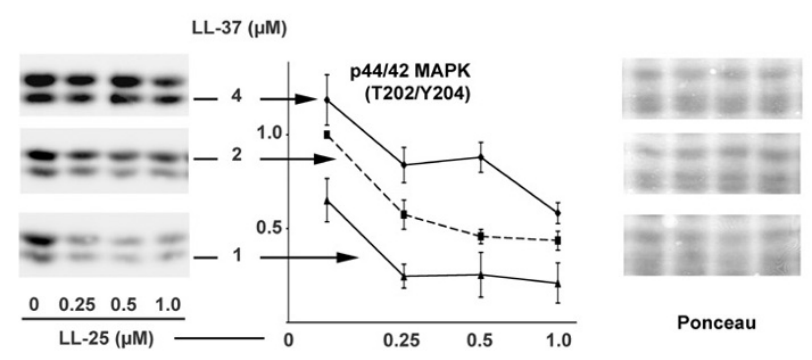

Ponceau

(d)
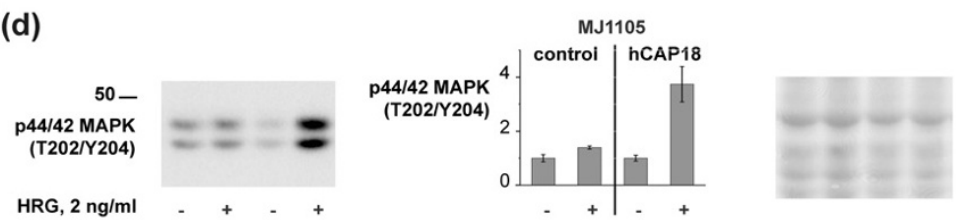

Ponceau

LL-37 synergistically enhances Heregulin-induced mitogen-activated protein kinase (MAPK) phosphorylation through the ERBB2 receptor. (a) Phosphorylation of ERBB2 (upper panel) and MAPK (lower panel) by treatment of ZR75-1 cells with LL-37 and Heregulin $\beta 3$ (HRG) on their own and in combination. The diagram shows the mean phosphorylation level as evaluated by Western blot analysis, normalised against Ponceau staining and relative to untreated samples. On the left side is shown one representative of the triplicates used for evaluation. The lower rows show Western blots against total ERBB2 and MAPK, demonstrating an unaltered protein level, and Ponceau staining of the corresponding sections of the blot. (b) Inhibition of MAPK activation in ZR75-1 by the ERBB inhibitor PD153035 but not by pertussis toxin or metalloprotease inhibitor GM6001. The arrow points to the histogram for PD153035 treatment. (c) LL-25 inhibits the LL-37 dependent activation of MAPK. Experiments were performed in the MJ1105 control cell line using HRG at $2 \mathrm{ng} / \mathrm{ml}$, and by varying the concentrations of both LL-37 and LL-25 as displayed. The diagram shows the levels of MAPK phosphorylation relative to the conditions of $2 \mu \mathrm{M}$ LL-37. (d) Synergistic effect between HRG and endogenous production of transgenic hCAP18 in the MCF-7 derivative MJ1105. For all experiments, the Ponceau staining used for normalisation is shown. All conditions were run in triplicates $(n=3)$, and in addition repeated at least on one independent occasion. 
Immunoblotting showed that the amount of ERBB2 and ERK $1 / 2$ protein remained unchanged, indicating that LL-37 and HGR did not affect their expression, only their activation (Figure $2 \mathrm{a})$.

A scrambled version of LL-37 [23] was without activity (not shown), confirming the specificity of LL-37 in our experiments. For LL-37, a micromolar concentration was required to achieve significant synergistic activity (data not shown). This concentration range of LL-37 was previously demonstrated to increase proliferation and migration of epithelial cells and to induce angiogenesis $[8,17,23]$.

PD153035, an inhibitor of tyrosine kinase activity of the ERBB family, blocked the HRG dependent MAPK activation (Figure $2 \mathrm{~b})$ at $2.5 \mu \mathrm{M}$. The activation of MAPK induced by LL-37 on its own was maintained, but the synergistic effect seen with both substrates was lost in the presence of PD153035 (Figure 2b). At $20 \mathrm{nM}$, a concentration sufficient to completely block the EGFR [24], PD153035 only caused a slight inhibition. Thus the EGFR does not seem to contribute significantly to the observed effect.

LL-37 has been shown to activate cell signalling through pertussis toxin sensitive $G$ proteins $[8,10,23]$. The activation of EGFR by LL-37 was previously demonstrated to involve the release of heparin-bound EGF by metalloproteases that were blocked with the inhibitor GM6001 [7]. Neither of these alternatives, however, seemed responsible for our findings, since the effect of LL-37 both in absence and presence of HRG was unaffected by pertussis toxin or GM6001 (Figure 2b). We also used the WRW4, an antagonist of LL-37 at the G-protein coupled receptor FPRL1 [25], and inhibitors against PKA, PKC and c-src, which can perform a crosstalk between ERBB2 and a G-protein coupled receptor [26]. In addition we tested inhibitors against reactive oxygen species, which can influence tumourigenicity by activating EGFR-related pathways [27]. The synergistic effect between LL-37 and HRG on the level of activated MAPK was unaffected by these treatments [see additional data file 3].

LL-25, a synthetic derivative of LL-37, lacking the 12 C-terminal amino acids, had a minimally stimulatory effect on the phosphorylation of MAPK on its own (not shown), but strongly inhibited the effects induced by LL-37 (Figure 2c). The inhibition was dependent on the LL-37/LL-25 molar ratio, and not on the absolute concentration of LL-25, suggesting that LL-25 serves as a competitive inhibitor of LL-37. A scrambled version of LL-37 [23] was without activity (not shown), confirming the specificity of LL-37 in our experiments.

MJ1105 cells showed a similar behaviour in this assay. However, the response to HRG was strongly elevated when hCAP18 was overexpressed from a transgene, indicating that transgenic expression partially replaced the exogenous addition from LL-37 (Figure 2d).

\section{LL-37 alters anchorage independent growth morphology of breast cancer cells}

To investigate whether LL-37 influences tumour cell behaviour, we studied the effect of LL-37 on colony formation of MJ1105, with or without transgenic hCAP18 expression, and ZR75-1 in soft agar. LL-37 in the presence or absence of HRG did not significantly affect the number of colonies, but profoundly affected their morphology irrespective of the cell line. In the presence of LL-37, colonies became less compact and were surrounded by satellites (shown for MJ1105 in Figure 3). This observation shows that LL-37 impacts the growth pattern of breast cancer cells and suggests that LL-37 promotes a migratory cell phenotype. The addition of $1 \mu \mathrm{M}$ LL-25, which was sufficient to substantially inhibit the LL-37-induced MAPK phosphorylation, significantly reduced the number of dispersed colonies (Figure 3 ). The three cell lines behaved similarly [see additional data file 4]. Thus, the LL-25 peptide inhibited not only MAPK activity induced by LL-37, but also the soft agar growth morphology of breast cancer cells.

\section{Figure 3}
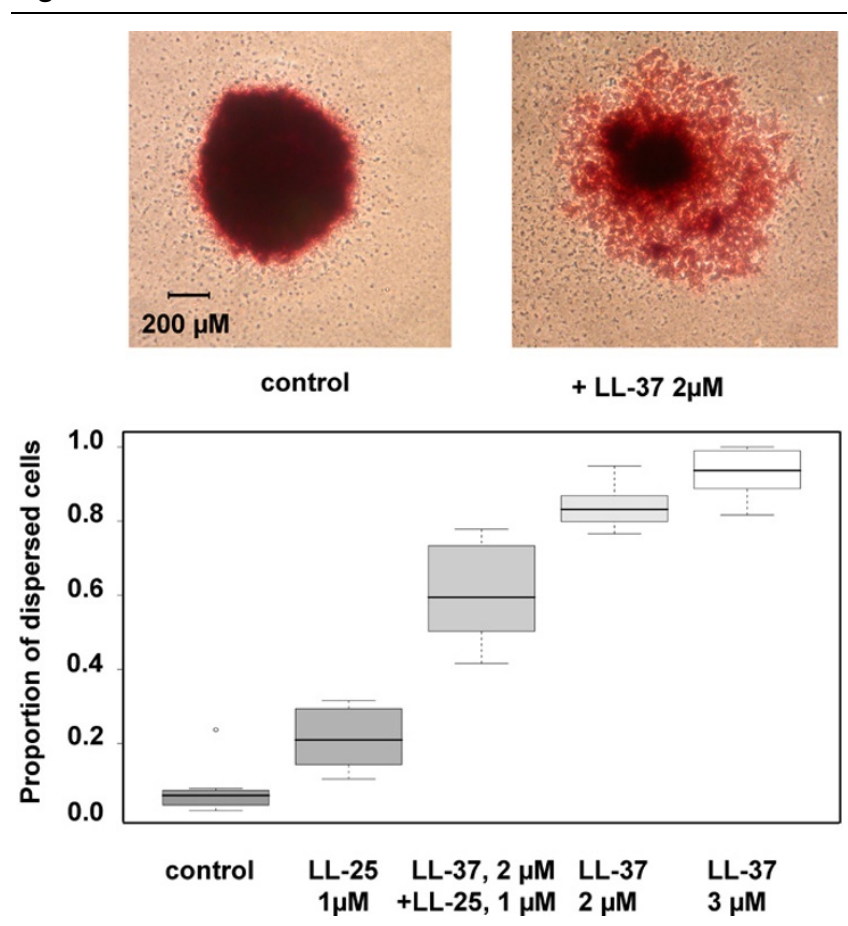

LL-37 induces morphological changes in MJ1105 soft agar clones. The upper row shows an example of a colony in absence and in presence of LL-37. For the quantitative evaluation displayed in the diagram, cell culture experiments for each condition $(n=8)$ were arranged in a factorial design and the resulting data analysed by analysis of variance

(ANOVA), the significance level set to $\alpha=0.05$. The proportion of cell colonies with LL-37 induced morphological alterations was significantly lower in presence of LL-25 $(p<0.01)$. The experiment was repeated on three independent occasions. 


\section{LL-37 stimulates the migration of breast cancer cells in vitro}

The change in cell colony phenotype was suggestive of an influence of LL-37 on cell migration, so we evaluated the effect of LL-37 on MCF7 breast cancer cell migration using a Boyden chamber assay. In this assay, the presence of $2 \mu \mathrm{M}$ LL-37 tripled the number of migrating MCF7 cells ( $p<0.001)$, compared with controls. In accordance with our in vivo data, the presence of LL-25 $(1 \mu \mathrm{M})$ abolished the migratory effect of LL37 ( $p<0.01$ ), thus confirming its inhibitory potential, although on its own LL-25 did not have a significant effect on cell migration (Figure 4).

\section{Overexpression of hCAP18 in breast cancer cells enhances metastasis formation in SCID mice}

To extend our in vitro findings to in vivo tumour growth and metastasis, we investigated the effect of hCAP18/LL-37 in a xenograft model. To this end, we established primary tumours with hCAP18 transgenic and control derivatives of MJ1105 cells in severe combined immunodeficiency (SCID) mice and monitored tumour growth and metastasis formation (Table 1 and Figure 5). As determined by RT-PCR, the transgenic cell line expressed hCAP18 at the level of high expressing breast

Figure 4

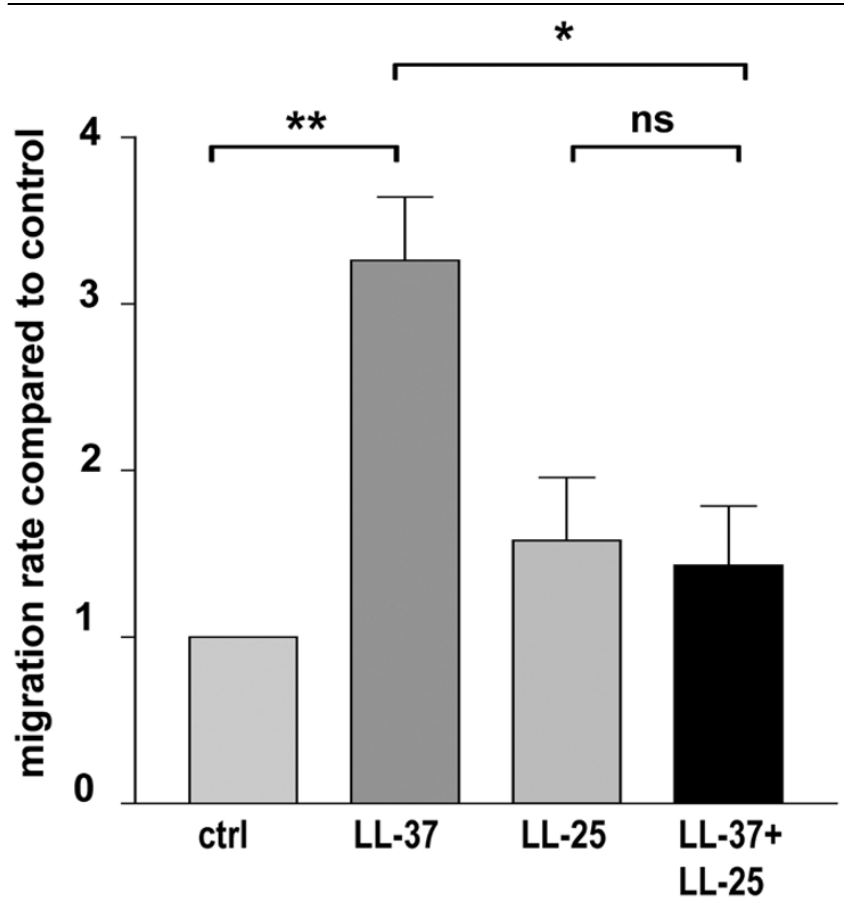

LL-37 at $2 \mu \mathrm{M}$ increases the migration of MCF-7 breast cancer cells in a Boyden Chamber assay. The stimulatory effect induced by LL-37 was abrogated when LL-25 at $1 \mu \mathrm{M}$ was added together with LL-37 in the lower chamber. Control experiments were with medium only in the lower chamber, or with LL-25 in the medium, respectively. The results are given as mean \pm standard error of the mean, $n=4 .{ }^{*} p<0.05,{ }^{* *} p$ $<0.01, \mathrm{~ns}=$ non significant. tumours, whereas the expression of the control cell line was at the level of unaffected breast tissue (Figure 5b).

In vitro, the colony formation assay did not show any distinguishable features for the transgenic lines [see additional data file 4]. In the mouse, however, we observed a significant difference between transgenic and control cells in metastasis formation (Table 1.) Four out of five mice injected with the hCAP18-overexpressing breast cancer cells developed metastases, three of them in multiple forms and/or loci (Table 1). Metastases were detected in lymph nodes, abdominal tumours, ascites fluid and EGFP-expressing MJ1105-hCAP18 cells in spleen and liver (Figure $5 \mathrm{a}$ and Table 1). In contrast, only one lymph node metastasis was detected in one of the mice injected with the control cells (Table 1), and this was located on the same side as the primary tumour. The presence of human breast cancer cells in all tumours and metastases was verified by detecting the expression of eGFP fluorescent marker in the ascites fluid (Figure $5 \mathrm{a}$ ), and by immunohistochemistry with anti-HLA-ABC antibodies (not shown) on the solid tumours.

High expression of $h C A P 18$ in all primary and secondary tumours of test mice injected with MJ1105 hCAP was verified by RT-PCR and confirmed by immunohistochemistry (Figure $5 \mathrm{~b}$ and additional data file 5). Some tumour regions stained weakly, even with HLA staining (not shown), indicating infiltration by mouse cells. Interestingly, in primary tumours from the control cell line, RT-PCR analysis of $h$ CAP18 mRNA showed a two-fold elevation compared with the expression in cell culture (Figure 5b). Immunohistochemistry revealed that hCAP18 was produced in small foci within all primary control tumours, thus confirming that spontaneous, local upregulation of hCAP18 occurred in these tumours in vivo (Figure 5b). No alteration of the ERBB2 transcription level, compared with the parental cell lines, was detected in control or test samples [see additional data file 2].

Western blot analysis revealed significant differences between primary tumours in test and control mice. The level of phosphorylated MAPK was higher $(\mathrm{p}<0.05)$ in $h$ CAP18 transgenic tumours compared with the control group. In the transgenic tumours, a decrease of phosphorylated p185 ERBB2 was found (Figure 5c) whereas a band of $65 \mathrm{kDa}$ was increased in intensity, indicative of ERBB2 degradation. An additional blot using antibodies against total ERBB2 showed the same image and thus confirmed that the bands indeed were derived from ERBB2 (not shown).

\section{Discussion}

Expanding from our previous findings, we demonstrate that $h C A P 18$ is highly expressed in breast cancer. Only few tumours expressed $h C A P 18 \mathrm{mRNA}$ within the range of control samples, and none of these showed evidence of metastases. Stratifying the material we found that in the ER-positive 
(a)

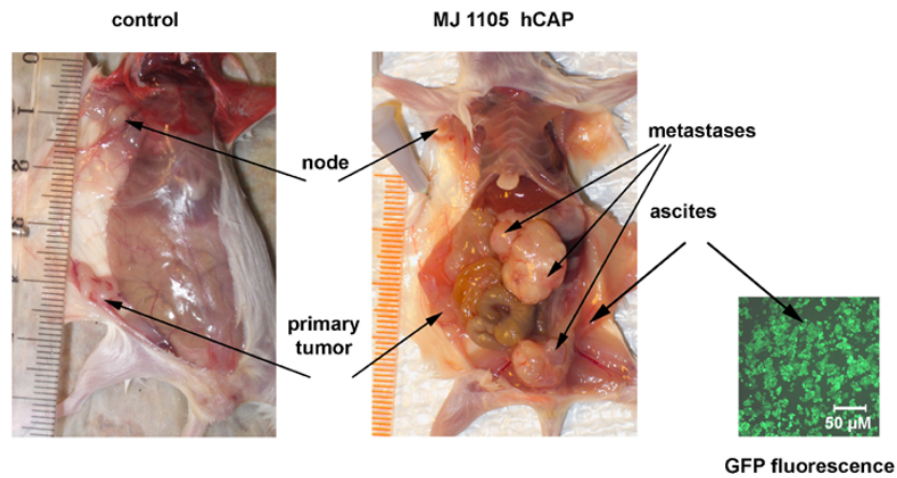

(b)

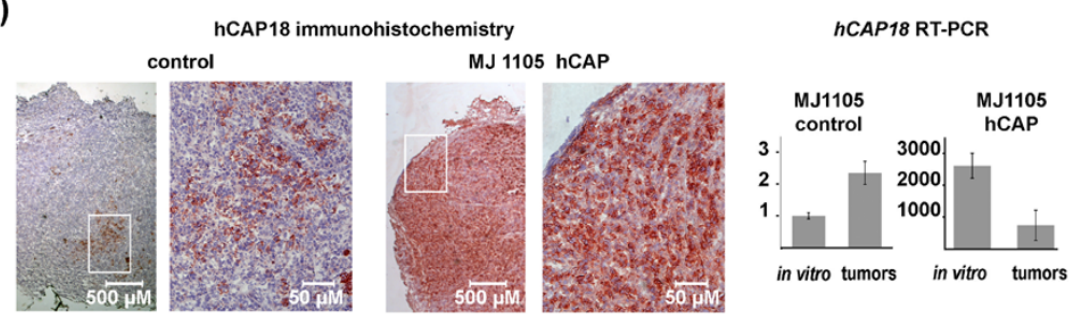

(c)

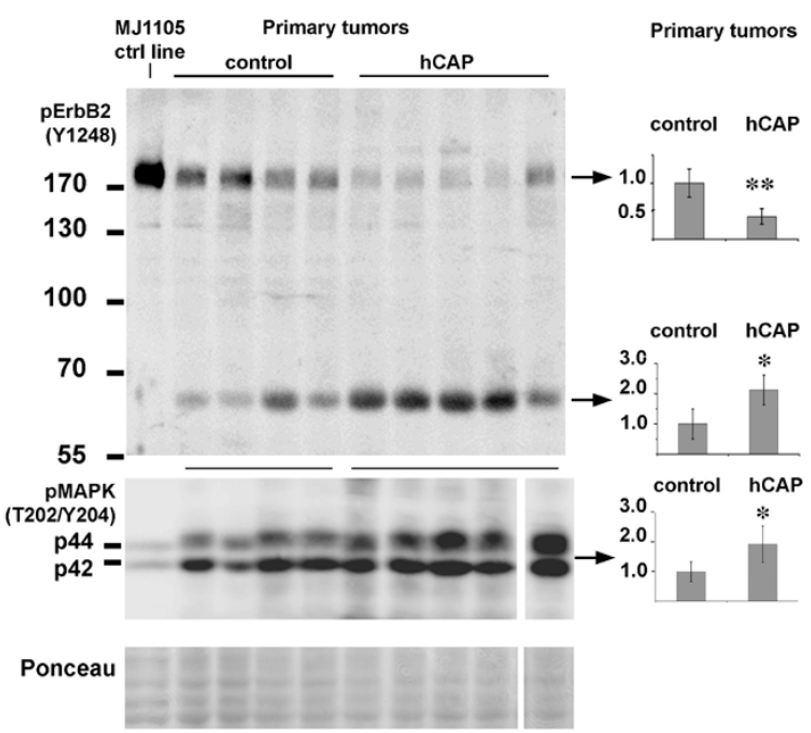

Overexpression of $h$ CAP18 in MJ1105 cells increases metastasis formation in severe combined immunodeficiency (SCID) mice. (a) Metastasis formation displayed in a mouse injected with MJ1105-hCAP18 cells compared with control mouse treated with MJ1105 lacking hCAP18. The right panel shows tumour cells from ascites fluid detected by fluorescent transgene-coupled enhanced green fluorescent protein (eGFP) expression. (b) Expression analysis of hCAP18/L-37 in mouse tumours. (Left) Immunohistochemistry with anti-LL-37 antibodies demonstrating strong expression in transgenic tumours, and minor local induction in control tumours. Right, the expression of $h$ CAP18 mRNA determined by reverse transcriptase PCR in tumours and transgenic cell lines. All comparisons are made to the expression of MJ1105 control cell line, which is set to one. (c) Western blot analysis demonstrates increased mitogen-activated protein kinase (MAPK) phosphorylation and increased degradation of phosphorylated ERBB2, in hCAP18 transgenic primary tumours compared with control primary tumours. On the left side of the blot, the control cell line is shown for comparison. Diagrams to the right illustrate the expression levels for respective tumour group, their statistic significance (two-tailed t-test, equal variance) indicated by asterix. 
Survey of mouse tumours derived from hCAP18 overexpressing MJ1105 and its control.

\begin{tabular}{|c|c|c|c|c|c|c|c|c|}
\hline Cell line & Mouse & $\begin{array}{c}\text { Sacrificed day } \\
\text { past inoculation }\end{array}$ & $\begin{array}{l}\text { Primary tumour } \\
\text { size }(\mathrm{mm})\end{array}$ & Metastases & $\begin{array}{l}\text { Lymph } \\
\text { nodes }\end{array}$ & $\begin{array}{l}\text { Ascites with } \\
\text { eGFP cells }\end{array}$ & $\begin{array}{l}\text { eGFP cells in } \\
\text { spleen }\end{array}$ & GFP cells in liver \\
\hline \multirow{5}{*}{$\begin{array}{l}\text { MJ 1105- } \\
\text { hCAP18 }\end{array}$} & h1 & 43 & $6 \times 6 \times 6$ & & & & & \\
\hline & h2 & 71 & $10 \times 8 \times 8$ & & & & + & + \\
\hline & h3 & 71 & $8 \times 8 \times 8$ & & 3 & & & + \\
\hline & h4 & 75 & $8 \times 8 \times 8$ & 3 abdominal & 2 & + & & \\
\hline & h5 & 90 & $8 \times 5 \times 4$ & & 1 & & & \\
\hline \multirow{4}{*}{$\begin{array}{l}\text { MJ1105 } \\
\text { eGFP }\end{array}$} & 11 & 43 & $10 \times 10 \times 10$ & & & & & \\
\hline & 12 & 43 & $8 \times 7 \times 6$ & & & & & \\
\hline & 13 & 90 & $7 \times 10 \times 6$ & & & & & \\
\hline & 14 & 90 & $8 \times 4 \times 4$ & & 1 & & & \\
\hline
\end{tabular}

For statistical evaluation, each visible metastasis or node, or the presence of fluorescent cells in ascites/spleen or liver, are counted as one event each. Using the Mann-Whitney U-test, the median number of metastatic events between the groups is significant $(p=0.05)$. eGFP = enhanced green fluorescent protein.

tumours, but not in ER-negative tumours, the level of hCAP18 expression was significantly higher in patients with lymph node metastasis. ER positivity is reported to be associated with more benign disease, so our findings may seem contradictory. However, breast cancer biology and heterogeneity remain insufficiently understood and still today, no single marker has been identified that will consistently predict prognosis. In fact, microarray studies have demonstrated that ER-positive tumours are a highly heterogeneous group, and that the overall favourable prognosis attributed to ER-positive status proved valid for a subgroup of tumours, whereas another group of ERpositive tumours was associated with poor outcome [28].

Of particular interest in this context is the recent identification of a 'wound response signature' that from established biomarkers such as tumour grade, lymph node status and ER-status, was shown to independently predict prognosis in breast cancer with significantly higher accuracy than established risk factors [29]. Specifically, it was shown that the expression of such a wound signature in breast tumours significantly affected metastasis potential and reduced survival. Considering that LL-37 is emerging as an integral part of the innate reaction to wounding, being rapidly and strongly upregulated in response to injury and also involved in the healing process, it can be hypothesised that similar cellular programs are at play in cancer progression.

Gene amplification and protein overexpression of the tyrosine kinase receptor ErbB2 is considered a hallmark of metastatic development and poor outcome in breast cancer [21]. Our data demonstrate a significant correlation between the transcription levels of $h C A P 18$ and ERBB2 genes in ER-positive as well as in ER-negative tumours. Despite this, there was no correlation for $h C A P 18$ or ERBB2 expression and survival at five-year follow-up in any of the groups, again underscoring the limitations using single transcription markers in predicting disease outcome.

The control breast cancer cells used for the mouse study have only marginal expression of hCAP18 when grown in vitro. However, after forming primary tumours at the site of cell injection, we detected a focal upregulation of hCAP18 mRNA and protein in all mouse control tumours (Figure $5 \mathrm{~b}$ ). This phenomenon supports the notion that upregulation of hCAP18 is a common event during breast cancer development, in agreement with our findings in the clinical samples. Recently LL-37 was shown to stabilise the Hypoxia-Inducible factor alpha, and consequently upregulate vascular endothelial growth factor, in human keratinocytes [30], thus linking LL-37 to hypoxia similar to its porcine counterpart PR39 [31]. Thus, one can hypothesise that hypoxia may be the biological basis for the upregulation of hCAP18/LL-37 that we observed in the mouse tumours.

Although our studies show that hCAP18/LL-37 synergistically enhances ERBB kinase signalling, the mechanism remains unknown. By the use of specific inhibitors (Figure 2b), we excluded the previously reported mechanisms of LL-37, that is the release of EGF-like factors through activation of metalloproteases and/or pertussis toxin sensitive activation of $G$ proteins. Based on similar studies on lung cancer cells [19] and in line with structural studies on LL-37 [32], it was suggested that LL-37 causes its effects by electrostatic interactions with the cell membrane rather than with a receptor. In our study, we 
have identified a truncated N-terminal peptide, LL-25, that acts as a potent inhibitor of both LL-37 signalling and of LL-37induced migration and alteration of cancer cell colony morphology. We find it difficult to understand how a fragment of LL-37 would inhibit membrane interactions, and favour the hypothesis that LL-37 interacts with ERBB kinases via a yet unidentified receptor. Still, a direct effect of LL-37 on the ERBB receptors cannot be excluded. Whatever the mechanism, the fact that the effects of LL-37 can be inhibited opens up the possibility of therapeutic targeting.

The results from the colony formation and migration assays confirm that LL-37 expression contributes to metastases, as hypothesised on the basis of our findings in the clinical samples. The soft agar growth pattern is indicative of cellular behaviour and the profound phenotypic changes induced by LL-37 peptide treatment, most likely reflect an enhanced migratory and invasive capacity in these cells. The colony morphology induced by LL-37 was strikingly similar to the growth pattern reported for a melanoma cell line exposed to EGF-like peptides [33], and for mammary epithelial cells overexpressing ERBB2 [34], which was hypothesised to mirror an increased metastatic potential [34]. The $2 \mu \mathrm{M}$ concentration of LL-37 used in this experiment is well below cytotoxic levels and was previously shown to stimulate cell proliferation and migration $[17,18]$. In contrast, to what was recently reported for lung cancer cells [19], we did not detect significant differences in the number of colonies after treatment with LL-37 which may be due to underlying biological differences between the cancer cell types utilised in these experiments. It should be highlighted that our analysis on breast tumour samples is presently the only one to show a correlation of $h C A P 18$ expression with a particular tumour cell phenotype, still pending study in other tumour types.

In accordance with the findings in the clinical studies and in the in vitro experiments, we found a significant increase in metastases in the SCID mice injected with the hCAP18 transgenic cell line. Not only did we detect lymph node metastases but also distant metastases indicative of lymphatic as well as haematic spread of tumour cells. The control breast cancer cells used for the mouse study have only marginal expression of hCAP18 when grown in vitro. However, after forming primary tumours at the site of cell injection, we detected a focal upregulation of hCAP18 mRNA and protein in all mouse control tumours indicating that local upregulation of hCAP18 occurred when these tumours formed in vivo (Figure $5 \mathrm{~b}$ ). This phenomenon supports the notion that upregulation of hCAP18 is a common event during breast cancer development, in agreement with our findings in the clinical samples.

Western blot analysis of the mouse tumours confirmed that the MAPK activation by hCAP18/LL-37 that we observed in vitro reflects events of in vivo tumourigenesis. The partial degradation of ERBB2 in overexpressing tumours is worthy of note. A reduced amount of intact protein, at a constant transcription rate, is characteristic of receptor degradation after activation and internalisation, as reported for ERBB2 following long-term ligand activation [35]. Truncated versions of ERBB2 have been shown to actively participate in signalling [36] and to be resistant to trastuzumab treatment in breast cancer [37].

We did not detect the presence of truncated ERBB2 in our MAPK activation assays, which may reflect that the activation time might have been too short to induce degradation. However, the cellular environment should also be considered: in the mouse the extracellular proteins or domains on the tumour cell surface are exposed to proteases from the surrounding stroma, which might contribute to their degradation, or in the case of hCAP18, its activation. This would also explain why transgenic $h C A P 18$ did not appear to alter the properties in the colony formation assay, but still induced metastasis formation in the mouse. In correlation with this hypothesis, recent studies show that the expression of metalloprotease MMP9 from the tumour surrounding stroma, unlike its expression in tumour cell cytoplasm, correlates with unfavourable prognosis in ERBB2 positive breast cancer [38].

The correlation between hCAP18 and ERBB2 expression that was observed in the human tumours did not occur in vitro or in the mouse model. We favour the hypothesis that the upregulation of both occurs independently, but due to their functional collaboration is selected for during the evolution of human breast cancer.

The role for hCAP18/LL-37 as a proinflammatory molecule in innate immunity is well established. In this context, LL-37 alerts the immune system in case of injury and microbial invasion. It is conceivable that broad defense strategies involving hCAP18/LL-37 evolved to provide sustained protection and prompt repair, aiming to fully restore tissue integrity. This would be consistent with our recent understanding of hCAP18/LL-37 as a stimulant of cell migration and proliferation and as a promoter of wound healing $[12,13]$. Thus, in view of the emerging link between chronic inflammation and cancer [14], hCAP18/LL-37 may contribute to cancer as a novel and versatile player, not only through its proinflammatory actions but also through its growth-factor like properties.

The data presented herein and recent observations in lung and ovarian cancer $[18,19]$, point to a role for hCAP18/LL-37 in cancer progression and spread. The underlying molecular mechanisms, however, remain to be clarified. hCAP18/LL-37 is emerging as a multifunctional molecule progressively implicated in multiple highly significant processes in cancer development. hCAP18/LL-37 may constitute a putative therapeutic target to prevent progression to metastatic disease. 


\section{Conclusions}

In summary, we show that hCAP18/LL-37 is highly upregulated in breast cancer correlating with the expression of ERBB2. In vitro, we also show that they are functionally connected, in that hCAP18/LL-37 amplifies MAPK signalling through ErbB2 and that treatment with LL-37 peptide alters the growth phenotype and stimulates the migration of breast cancer cells. Finally, overexpressing hCAP18 in a low malignant breast cancer cell line promotes metastatic disease in a SCID mouse model. Taken together, our data expand on recent findings in lung and ovarian cancers and demonstrate a novel role for the single human cathelicidin protein hCAP18/ LL-37 in breast cancer.

\section{Competing interests}

MS is a founder of Lipopeptide AB, a company that develops pharmaceuticals based on LL-37 for wound healing. GW and MS are inventors of patents identifying LL-37 as a potential target in cancer. GW and MS have transferred the above mentioned patent rights to Karolinska Development which now owns these rights.

\section{Authors' contributions}

MS and GW are responsible for developing the hypothesis and writing the manuscript and GW for planning and executing the experiments. FG performed the statistical analysis of the tumours and their expression. $\mathrm{AL}$ and $\mathrm{SR}$ collected and evaluated the clinical material. FS supported the analysis of the mouse experiments and performed the statistics for the molecular analysis. CIC performed FACS analysis and supported the setup of the transgenic lines. AP contributed to the critical evaluation and interpretation of data. SZ performed part of the inhibitory studies and characterisation of cell lines. ZS and RM performed the migration assay.

\section{Additional files}

The following Additional files are available online:

\section{Additional file 1}

A MS Word file containing a table that lists the human tumours and cell lines used in this study. The transcription levels of hCAP18 and ERBB2 as determined by RT-PCR are displayed relative to the mean of the four unaffected breast tissue control samples. n.d. = not done.

See http://www.biomedcentral.com/content/ supplementary/bcr2221-S1.doc

\section{Additional file 2}

A MS Word file containing a table that lists the transcription levels of hCAP18 and ERBB2 in mouse tumours. The values are relative to the MJ1105 control cell line as determined by RT-PCR, and normalised against total RNA as determined by $18 \mathrm{~S}$.

See http://www.biomedcentral.com/content/ supplementary/bcr2221-S2.doc

\section{Additional file 3}

A pdf file containing a figure of a Western blot analysis excluding cross-talk mechanisms for the synergistic effect of LL-37 and HRG on MAPK phosphorylation. (a) The analysis on ZR75-1 cells stimulated with LL-37 and/ or HRG after 30 minutes pretreatment with inhibitors as indicated. The concentration of inhibitors is listed together with their prime targets. (b) The evaluation of the effect of WRW4, untreated samples being run sideby-side with treated samples to exclude even minimal differences. All experiments were run in triplicates $(n=$ $3)$, and repeated at one independent occasion.

See http://www.biomedcentral.com/content/ supplementary/bcr2221-S3.pdf

\section{Additional file 4}

A pdf file containing a figure displaying the rate of morphological changes in soft agar clones from ZR75-1, MJ1105 control and hCAP18 transgenic cells, as evaluated in Figure $3(n=4)$.

See http://www.biomedcentral.com/content/ supplementary/bcr2221-S4.pdf

\section{Additional file 5}

A pdf file containing a figure showing the immunohistochemical analysis with anti-LL-37 antibodies on all mouse tumours in this study. See http://www.biomedcentral.com/content/ supplementary/bcr2221-S5.pdf

\section{Acknowledgements}

We thank Professor Annika Lindblom for kindly providing the RNA from the breast tumour samples, Anna-Lena Kastman for performing the immunohistochemistry on mouse tumours, and Margareta Hagelin, MTC animal center, for skillful assistance during our mouse studies. Alvar Grönberg and Max Petersson are acknowledged for constructive discussions and Mikala Egeblad is thankfully acknowledged for providing MCF7 derivatives. The study was supported by grants from the Karolinska University Hospital and Karolinska Institutet, Welander-Finsen Foundation, King Gustaf V Jubilee Fund, The Scientific Association for Development, Le STUDIUM, Institute for Advanced Studies in Région Centre, and the Ligue Nationale Française contre le Cancer. 


\section{References}

1. Gudmundsson GH, Agerberth B, Odeberg J, Bergman T, Olsson $B$, Salcedo R: The human gene FALL39 and processing of the cathelin precursor to the antibacterial peptide LL-37 in granulocytes. Eur J Biochem 1996, 238:325-332.

2. Yamasaki K, Schauber J, Coda A, Lin H, Dorschner RA, Schechter NM, Bonnart C, Descargues P, Hovnanian A, Gallo RL: Kallikreinmediated proteolysis regulates the antimicrobial effects of cathelicidins in skin. Faseb J 2006, 20:2068-2080.

3. Sorensen OE, Follin P, Johnsen AH, Calafat J, Tjabringa GS, Hiemstra PS, Borregaard N: Human cathelicidin, hCAP-18, is processed to the antimicrobial peptide LL-37 by extracellular cleavage with proteinase 3. Blood 2001, 97:3951-3959.

4. Sorensen $O E$, Gram L, Johnsen $A H$, Andersson $E$, Bangsboll $S$, Tjabringa GS, Hiemstra PS, Malm J, Egesten A, Borregaard N: Processing of seminal plasma hCAP-18 to ALL-38 by gastricsin: a novel mechanism of generating antimicrobial peptides in vagina. J Biol Chem 2003, 278:28540-28546.

5. Cowland JB, Johnsen AH, Borregaard N: hCAP-18, a cathelin/ pro-bactenecin-like protein of human neutrophil specific granules. FEBS Lett. 1995, 36:173-176.

6. Frohm M, Agerberth B, Ahangari G, Stahle-Backdahl M, Liden S, Wigzell $\mathrm{H}$, Gudmundsson $\mathrm{GH}$ : The expression of the gene coding for the antibacterial peptide LL-37 is induced in human keratinocytes during inflammatory disorders. J Biol Chem 1997, 272:15258-15263.

7. Tjabringa GS, Aarbiou J, Ninaber DK, Drijfhout JW, Sorensen OE, Borregaard N, Rabe KF, Hiemstra PS: The antimicrobial peptide LL-37 activates innate immunity at the airway epithelial surface by transactivation of the epidermal growth factor receptor. J Immunol 2003, 171:6690-6696.

8. Tokumaru S, Sayama K, Shirakata Y, Komatsuzawa H, Ouhara K, Hanakawa Y, Yahata Y, Dai X, Tohyama M, Nagai H, Yang L, Higashiyama S, Yoshimura A, Sugai M, Hashimoto K: Induction of keratinocyte migration via transactivation of the epidermal growth factor receptor by the antimicrobial peptide LL-37. J Immunol 2005, 175:4662-4668.

9. De Y, Chen Q, Schmidt AP, Anderson GM, Wang JM, Wooters J, Oppenheim JJ, Chertov O: LL-37, the neutrophil granule- and epithelial cell-derived cathelicidin, utilizes formyl peptide receptor-like 1 (FPRL1) as a receptor to chemoattract human peripheral blood neutrophils, monocytes, and T cells. J Exp Med 2000, 192:1069-1074

10. Shaykhiev R, Beisswenger C, Kandler K, Senske J, Puchner A, Damm T, Behr J, Bals R: Human endogenous antibiotic LL-37 stimulates airway epithelial cell proliferation and wound closure. Am J Physiol Lung Cell Mol Physiol 2005, 289:L842-848.

11. Tjabringa GS, Ninaber DK, Drijfhout JW, Rabe KF, Hiemstra PS: Human cathelicidin LL-37 is a chemoattractant for eosinophils and neutrophils that acts via formyl-peptide receptors. Int Arch Allergy Immuno/ 2006, 140:103-112.

12. Carretero M, Escamez MJ, Garcia M, Duarte B, Holguin A, Retamosa $\mathrm{L}$, Jorcano JL, Rio MD, Larcher F: In vitro and in vivo wound healing-promoting activities of human cathelicidin LL-37. J Invest Dermato/ 2008, 128:223-236.

13. Heilborn JD, Nilsson MF, Kratz G, Weber G, Sorensen O, Borregaard N, Stahle-Backdahl M: The cathelicidin anti-microbial peptide LL-37 is involved in re-epithelialization of human skin wounds and is lacking in chronic ulcer epithelium. J Invest Dermatol 2003, 120:379-389.

14. Perwez Hussain S, Harris CC: Inflammation and cancer: an ancient link with novel potentials. Int J Cancer 2007, 121:2373-2380.

15. Okumura $K$, Itoh A, Isogai $E$, Hirose $K$, Hosokawa $Y$, Abiko $Y$, Shibata T, Hirata M, Isogai H: C-terminal domain of human CAP18 antimicrobial peptide induces apoptosis in oral squamous cell carcinoma SAS-H1 cells. Cancer Lett 2004, 212:185-194.

16. Winder D, Gunzburg WH, Erfle V, Salmons B: Expression of antimicrobial peptides has an antitumour effect in human cells. Biochem Biophys Res Commun 1998, 242:608-612.

17. Heilborn JD, Nilsson MF, Jimenez $\mathrm{Cl}$, Sandstedt $\mathrm{B}$, Borregaard $\mathrm{N}$, Tham E, Sorensen OE, Weber G, Stahle M: Antimicrobial protein hCAP18/LL-37 is highly expressed in breast cancer and is a putative growth factor for epithelial cells. Int J Cancer 2005, 114:713-719.
18. Coffelt SB, Waterman RS, Florez L, Bentrup KH, Zwezdaryk KJ, Tomchuck SL, Lamarca HL, Danka ES, Morris CA, Scandurro AB: Ovarian cancers overexpress the antimicrobial protein hCAP18 and its derivative LL- 37 increases ovarian cancer cell proliferation and invasion. Int J Cancer 2008, 122:1030-1039.

19. von Haussen J, Koczulla R, Shaykhiev R, Herr C, Pinkenburg O, Reimer D, Wiewrodt R, Biesterfeld S, Aigner A, Czubayko F, Bals $\mathrm{R}$ : The host defence peptide LL-37/hCAP-18 is a growth factor for lung cancer cells. Lung Cancer 2008, 59:12-23.

20. Egeblad M, Jaattela M: Cell death induced by TNF or serum starvation is independent of ErbB receptor signaling in MCF-7 breast carcinoma cells. Int J Cancer 2000, 86:617-625.

21. Slamon DJ, Clark GM, Wong SG, Levin WJ, Ullrich A, McGuire WL: Human breast cancer: correlation of relapse and survival with amplification of the HER-2/neu oncogene. Science 1987, 235:177-182.

22. Lacroix M, Leclercq G: Relevance of breast cancer cell lines as models for breast tumours: an update. Breast Cancer Res Treat 2004, 83:249-289.

23. Koczulla R, von Degenfeld G, Kupatt C, Krotz F, Zahler S, Gloe T, Issbrucker K, Unterberger $P$, Zaiou M, Lebherz C, Karl A, Raake $P$ Pfosser A, Boekstegers P, Welsch U, Hiemstra PS, Vogelmeier C, Gallo RL, Clauss M, Bals R: An angiogenic role for the human peptide antibiotic LL-37/hCAP-18. J Clin Invest 2003, 111:1665-1672.

24. Bos M, Mendelsohn J, Kim YM, Albanell J, Fry DW, Baselga J: PD15 a tyrosine kinase inhibitor, prevents epidermal growth factor receptor activation and inhibits growth of cancer cells in a receptor number-dependent manner. Clin Cancer Res 3035 , 3:2099-2106.

25. Bae YS, Lee HY, Jo EJ, Kim Jl, Kang HK, Ye RD, Kwak JY, Ryu SH: Identification of peptides that antagonize formyl peptide receptor-like 1-mediated signaling. J Immunol 2004, 173:607-614.

26. Drube S, Stirnweiss J, Valkova C, Liebmann C: Ligand-independent and EGF receptor-supported transactivation: lessons from beta2-adrenergic receptor signalling. Cell Signal 2006, 18:1633-1646.

27. Finch JS, Tome ME, Kwei KA, Bowden GT: Catalase reverses tumorigenicity in a malignant cell line by an epidermal growth factor receptor pathway. Free Radic Biol Med 2006, 40:863-875.

28. Sørlie T, Perou CM, Tibshirani R, Aas T, Geisler S, Johnsen $H$, Hastie T, Eisen MB, Rijn M van de, Jeffrey SS, Thorsen T, Quist $H$, Matese JC, Brown PO, Botstein D, Eystein Lønning P, BørresenDale AL: Gene expression patterns of breast carcinomas distinguish tumor subclasses with clinical implications. Proc Nat/ Acad Sci USA 2001, 98:10869-10874.

29. Chang HY, Nuyten DS, Sneddon JB, Hastie T, Tibshirani R, Sorlie $T$, Dai H, He YD, van't Veer LJ, Bartelink H, Rijn M van de, Brown $\mathrm{PO}$, Vijver MJ van de: Robustness, scalability, and integration of a wound-response gene expression signature in predicting breast cancer survival. Proc Natl Acad Sci USA 2005, 102:3738-3743.

30. Rodriguez-Martinez S, Cancino-Diaz JC, Vargas-Zuniga LM, Cancino-Diaz ME: LL-37 regulates the overexpression of vascular endothelial growth factor (VEGF) and c-IAP-2 in human keratinocytes. Int J Dermato/ 2008, 47:457-462.

31. Li J, Post M, Volk R, Gao Y, Li M, Metais C, Sato K, Tsai J, Aird W, Rosenberg RD, Hampton TG, Sellke F, Carmeliet P, Simons M: PR39, a peptide regulator of angiogenesis. Nat Med 2000, 6:49-55.

32. Li X, Li Y, Han H, Miller DW, Wang G: Solution structures of human LL-37 fragments and NMR-based identification of a minimal membrane-targeting antimicrobial and anticancer region. J Am Chem Soc 2006, 128:5776-5785.

33. De Larco JE, Pigott DA, Lazarus JA: Ectopic peptides released by a human melanoma cell line that modulate the transformed phenotype. Proc Natl Acad Sci USA 1985, 82:5015-5019.

34. D'Souza B, Taylor-Papadimitriou J: Overexpression of ERBB2 in human mammary epithelial cells signals inhibition of transcription of the E-cadherin gene. Proc Natl Acad Sci USA 1994, 91:7202-7206.

35. Magnifico A, Tagliabue E, Ardini E, Casalini P, Colnaghi MI, Menard S: Heregulin beta1 induces the down regulation and the ubiquitin-proteasome degradation pathway of p185HER2 oncoprotein. FEBS Lett 1998, 422:129-131. 
36. Egeblad M, Mortensen $\mathrm{OH}$, Jaattela M: Truncated ErbB2 receptor enhances ErbB1 signaling and induces reversible, ERKindependent loss of epithelial morphology. Int J Cancer 2001, 94:185-191.

37. Scaltriti M, Rojo F, Ocana A, Anido J, Guzman M, Cortes J, Di Cosimo S, Matias-Guiu X, Ramon y Cajal S, Arribas J, Baselga J: Expression of p95HER2, a truncated form of the HER2 receptor, and response to anti-HER2 therapies in breast cancer. $J$ Natl Cancer Inst 2007, 99:628-638.

38. Mylona E, Nomikos A, Magkou C, Kamberou M, Papassideri I, Keramopoulos A, Nakopoulou L: The clinicopathological and prognostic significance of membrane type 1 matrix metalloproteinase (MT1-MMP) and MMP-9 according to their localization in invasive breast carcinoma. Histopathology 2007, 50:338-347. 